
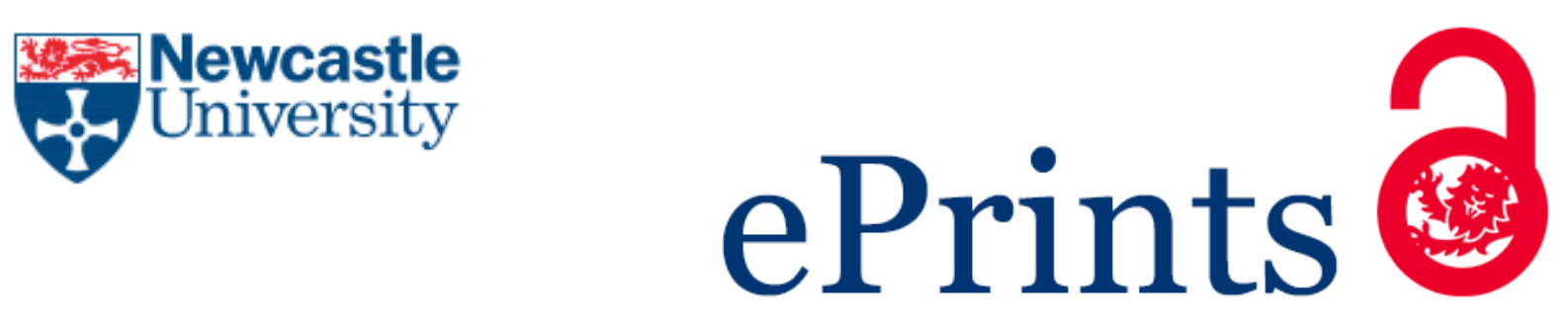

Purvis G, Gray N, Sano N, Barlow A, Cockell C, Abbott GD, van der Land C, Cumpson P.

Decontamination of geological samples by gas cluster ion beam etching or ultra violet/ozone.

Chemical Geology 2017, 466, 256-262.

\title{
Copyright:
}

(C)2017. This manuscript version is made available under the CC-BY-NC-ND 4.0 license

DOI link to article:

https://doi.org/10.1016/i.chemgeo.2017.06.016

Date deposited:

$25 / 08 / 2017$

Embargo release date:

23 June 2018

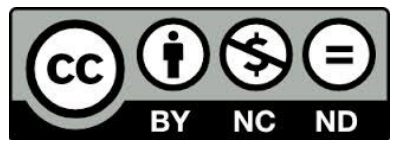

This work is licensed under a

Creative Commons Attribution-NonCommercial-NoDerivatives 4.0 International licence 


\section{Decontamination of Geological Samples by Gas cluster Ion Beam Etching or Ultra}

Violet/Ozone.

Graham Purvis $^{1 *}$, Neil Gray ${ }^{1}$, Naoko Sano ${ }^{2}$, Anders Barlow ${ }^{2}$, Charles Cockell ${ }^{3}$, Geoffrey D.

Abbott $^{1}$, Cees van der Land ${ }^{1}$ and Peter Cumpson ${ }^{2}$

${ }^{1}$ School of Civil Engineering and Geosciences, Devonshire Building Newcastle University, Newcastle-upon-Tyne, NE1 7RU

${ }^{2}$ National EPSRC XPS User's Service (NEXUS), Stephenson Building, Newcastle University, Newcastle-upon-Tyne, NE1 7RU

${ }^{3}$ UK Centre for Astrobiology, School of Physics and Astronomy, James Clerk Maxwell Building, the King's Buildings, University of Edinburgh.

*Corresponding author: g.w.h.purvis@ncl.ac.uk

Running title: Decontamination using GCIB or UV/O

Organic Material Removed by GCIB or UV/O 


\begin{abstract}
The organic matter within rocks contains chemical and isotopic evidence of its provenance, including information on past and extant life. Such information could further the understanding of life on the early Earth and yield evidence of the existence of past life on Mars. However, the collection of geological samples and subsequent transfer to analytical facilities possibly via long-term storage provides ample opportunity for organic contamination from a variety of sources prior to analysis. Erroneous assignment of organic contamination as authentic indigenous organic material is a significant issue in any geological specimen, but is exacerbated in rocks containing trace levels. This investigation evaluated two decontamination methods for geological samples, namely, the recently developed gas cluster ion beam etching, which supersedes monoatomic sputter etching, and ultra violet/ozone cleaning. Decontamination evaluation involved removal of intentionally applied organic contamination applied to basalt which initially possessed only trace levels of indigenous organic material. Pyrolysis-gas chromatography/mass spectrometry, and X-ray photoelectron spectroscopy were used to measure contaminant removal. Both techniques are suitable for removing organic contamination during the preparation of geological samples.
\end{abstract}

Key Words:

Decontamination

GCIB

$\mathrm{UV} / \mathrm{O}$

XPS

Py-GCMS

Organic Material Removed by GCIB or UV/O 


\section{INTRODUCTION}

Analysis of organic matter embedded in rocks can provide information regarding its origins. Of particular importance are molecular biomarkers which are linked to past or present biological activity (Eglinton, 1964; Eigenbrode, 2007; Summons et al., 2007). Biomarkers can provide insights into the identity and processes associated with fossils on the Earth (Brocks et al., 1999; Briggs and Summons, 2014) and could potentially provide evidence for past life on Mars (Summons et al, 2011). Consequently, it is essential that biomarkers detected are actually indigenous to the host rock in question and are distinguished from those that were subsequently introduced from non-indigenous natural processes or during sample removal, storage, and preparation for analysis (Brocks and Banfield, 2007; Sherman et al., 2007).

Decontamination of acquisition equipment is vital (Eigenbrode, et al 2009) as is the scrupulous decontamination of geological samples after removal from the environment, for example, during the sampling of sectioned drill cores. Chemicals such as chromic acid or organic solvents are frequently employed to clean geological samples but these can be hazardous and risk the deposition of adventitious carbonaceous material. When rocks contain only trace levels of indigenous organic matter $(<100 \mathrm{ppb})$ unintentional addition of organic matter makes a significant contribution to the net organic inventory, which may be erroneously identified. Furthermore, indigenous organic matter is often found in small and precious fossils and meteorites, which require minimally destructive decontamination protocols. This study tested two methods usually employed in surface cleaning for analysis of semiconductors in Materials Science. Specifically, the recently developed argon gas cluster ion beam (GCIB) etching, which removes surface contamination more gently than earlier monoatomic etching, and ultra violet ozone (UV/O), to decontaminate the surface layers of geological samples contaminated during acquisition and storage.

\subsection{Gas cluster ion beam etching}

Monatomic ion beam sputter etching has previously been employed to physically remove surface contamination from semi-conductors (e.g. Czanderna, 2012; Taborelli, 2007) and has even been applied to a tuff sample prior to analysis (Preston 2011). However, for this technique, individual high energy ions are propelled up to $20 \mathrm{~nm}$ into surfaces which may force surface material deeper into the sample, thus mixing any surface adventitious contamination with any underlying indigenous organic material of interest. Furthermore, the concentrated energy will break chemical

\section{Organic Material Removed by GCIB or UV/O}


bonds, destroying chemical and molecular information. This is problematic for the $1-10 \mathrm{~nm}$ and 1 $\mathrm{nm}$ analysis depths, encompassed by surface analytical techniques such as X-ray Photoelectron Spectroscopy (XPS) and Time of Flight Secondary Ion Spectroscopy (ToF SIMS) respectively. ToF SIMS is unable to make accurate quantitative measurements to the level required in this study, without the extensive use of reference authentic standards. Therefore, its use was outside the scope of this quantitative study (Briggs and Grant, 2003; Garrison and Postawa, 2013; Postawa, 2003 Rabbani et al, 2011)

The drawbacks with monatomic sputtering have been mitigated by the recently developed argon gas cluster ion beam (GCIB), which creates a beam consisting of clusters of 1000 argon atoms with a single charge, rather than individual argon ions. The energy is thus distributed across all atoms in the cluster therefore greatly reducing the damage depth created by the atoms in the cluster. Consequently, a crater only a few nm deep in the surface of the sample can be created. The depth of the crater is dependent upon on several factors such as the cluster size, the impact energy and the composition of the target sample. This process removes material in the predefined area exposed to the gas clusters (Cheng and Winograd, 2006; Cheng et al, 2006; Yamada et al, 2001). Damage to chemical bonds in organic compounds caused by GCIB is minimal and, therefore, the chemical states of the target material are available for analysis (Barlow et al, 2014; Counsell et al, 2014; Mahoney, 2010; Miyayama et al, 2010; Shard et al 2012; Shard et al 2015; Winograd, 2013; Yamada et al, 2001).

GCIB is routinely used to clean semiconductors, but it has been recently applied for decontaminating geological samples, prior to the surface analysis of paleobiological and astrobiological significance (Sano, 2016). Here GCIB has been used for the first time within an XPS instrument in order to rigorously evaluate its effectiveness at decontamination.

\subsection{Ultra violet light and ozone (UV/O) cleaning}

Ultraviolet-ozone (UV/O) cleaning, utilises a combination of UV light to photolytically breakdown organic material, and ozone that fully oxidises the breakdown products (Vig, 1985) to decontaminate the entire surface of a sample. UV/O has been used for many cleaning applications (Vig, 1985, Cumpson and Seah 1996) including olivine and feldspar geological samples, albeit without rigorous evaluation (Nugent et al, 1998; Hausrath et al, 2007). Here UV/O decontamination of basalt was evaluated using XPS and pyrolysis-gas chromatography mass

\section{Organic Material Removed by GCIB or UV/O}


spectrometry (py-GCMS), an analytical technique which identifies molecular information in organic compounds from a bulk sample e.g. (Mason et al., 2009).

\subsection{Intentional Contamination for Evaluating Decontamination Methods}

The strategy adopted in this study was to use WD40 to deliberately contaminate a low indigenous organic carbon basalt sample. WD40, a commercially available silicon lubricant, commonly used to clean and lubricate cutting tools, was previously employed to evaluate the decontamination of silicon wafers by UV/O cleaning (Cumpson and Sano, 2013). The organic components in WD40 that evaporate at temperatures $<100{ }^{\circ} \mathrm{C}$ at atmospheric pressure, will evaporate when they are exposed to the ultra-high vacuum of the XPS instrument analysis chamber, leaving a residue of low volatility high molecular weight organic compounds. So, although WD40 is not a contaminant encountered in standard geological investigations, in chemical terms, its residue represents a particularly difficult contaminant to remove compared to, for example, a pure low molecular weight hydrocarbon. Additionally, the levels of intentional contamination used in this study were in excess of what might be encountered during geological sample preparation and storage. This intentional contamination therefore provides a greater challenge for both GCIB etching and UV/O cleaning than would be anticipated in typical investigations acting as a 'worst case scenario'. The decontamination efficiency was determined by measuring the decrease in the carbon concentration relative to those of the other elements which constitute the parent rock.

\section{METHODS}

\subsection{Sample Acquisition, Preparation, Storage and Intentional Contamination}

The Whin Sill is a 295 Ma tholeiitic quartz dolerite intrusion in northern England, (Fitch, 1967; Liss et al., 2004) which contains trace amounts of indigenous organic carbon readily distinguishable from the increased carbon concentrations resulting from intentional contamination by WD40. A $1000 \mathrm{~g}$ piece of basalt was removed from exposed coastal Whin Sill (WSB) at Craster, Northumberland, UK, $\left(\mathrm{N}^{\circ} 5^{\circ} 28.427^{\prime} 00135.577^{\prime} \mathrm{W}\right)$. The WSB emplaced in Carboniferous strata was exposed by glacial erosion approximately 17000 years ago (Bateman $e t$ al, 2015; Goulty, 2005). Potentially, organic material dissolved in water could be absorbed, then deposited into the surface of rock, to depths greater than those which could be removed using the methods described here. Accordingly, the outer 5-10 mm environment exposed surface was

\section{Organic Material Removed by GCIB or UV/O}


trimmed from the parent sample, revealing un-weathered internal surfaces of basalt, which were then trimmed to $\sim 10 \mathrm{~mm} \times 10 \mathrm{~mm} \times 5 \mathrm{~mm}$ pieces, mimicking the acquisition of rock from sectioned core samples. Cutting was carried out using a Norton Clipper power saw and nitrile gloves were worn at all times. Trimmed pieces were handled with flamed forceps, before storage in glass vials sealed with $\mathrm{Al}$ foil cleaned by sonication for 30 minutes in dichloromethane and allowed to dry and closed under screw top lids. Vials were orientated upright during storage and transport, to prevent these 'as received' samples (designated WSB_AR) inadvertently contacting the foil seals.

The faces of WSB_AR samples were photographed to record which face of the basalt piece had been intentionally contaminated. A section of absorbent paper was sprayed with WD40, saturating the paper, then a piece of trimmed basalt was lightly pressed onto the paper for 10 seconds. These 'intentionally contaminated' pieces (designated as WSB_IC) were then air dried (10 minutes) and stored in the same way as WSB_AR.

\subsection{Decontamination by GCIB Etching}

Samples were decontaminated within 4 hours of intentional contamination using GCIB etching then evaluated using XPS. The GCIB etching was conducted on WSB_AR in triplicate, and on WSB_IC using a protocol adapted from Barlow et al (2014). The GCIB source was a Thermo Scientific ${ }^{\text {tm }}$ MAGCIS ${ }^{\text {tm }}$ gun within the XPS instrument, operated at $4 \mathrm{keV}$ generating a broad, semi-log distribution of argon cluster sizes centred on 1000 atoms per cluster at an input pressure of 4 bar. Neutral atoms are not expected to escape from the MAGCIS ${ }^{\text {tm }}$ due to a $2^{\circ}$ bend in the ion optics. Furthermore, argon clusters with multiple charges were not expected to be stable enough to emerge from the source. The beam current was stable around $20 \mathrm{nA} \pm 2 \mathrm{nA}$ (as measured at the sample plate within the instrument). An ion beam raster of $1 \mathrm{~mm} \times 2 \mathrm{~mm}$ was used, with an X-ray spot size of $200 \times 400 \mu \mathrm{m}$., providing a gap of $0.4 \mathrm{~mm}$ and $0.8 \mathrm{~mm}$ between the perimeter of the GCIB etch area and the perimeter of the XPS analysis, i.e. comfortably within the area of the sputter crater. Z-axis depth profiles were obtained by GCIB sputter etching with survey XPS analyses immediately conducted between each sputter etch treatment. The GCIB was rastered over the WSB_IC sample in 19 x 10 second increments for a total of 190 seconds. Additionally, The WSB_AR samples were etched in 4 x 30 second intervals for a total of 120 seconds, on three separate trimmed pieces.

\section{Organic Material Removed by GCIB or UV/O}




\subsection{XPS analysis}

XPS analysis was conducted using a Thermo Scientific K-alpha X-ray photoelectron spectrometer $^{\mathrm{tm}}$ (Thermo Scientific, East Grinstead, UK). Survey spectra (broad energy, multiple elements) were used to obtain the WSB_IC and WSB_AR elemental data obtained with scans between $-5.0 \mathrm{eV}$ and $1350.0 \mathrm{eV}$; a dwell time of $50 \mathrm{~ms}$; a step size of $1.0 \mathrm{eV}$ and; a pass energy of $200.0 \mathrm{eV}$. High resolution (narrow energy, single element) carbon 1s spectra were collected at 40 $\mathrm{eV}$ pass energy with a $0.1 \mathrm{eV}$ step size. Spectra were acquired using a monochromatic $\mathrm{Al} \mathrm{K \alpha}$ x-ray source with an output energy of $1486.6 \mathrm{eV}$ with a maximum $\mathrm{x}$-ray beam spot size of $400 \mu \mathrm{m}$. Surface charge compensation was obtained with a low energy dual-beam electron/ion flood gun operated at $40 \mathrm{eV}$.

Spectral analysis was carried out using CasaXPS software (Teignmouth, UK) with major peaks selected for element identification using the Handbook of X-ray photoelectron spectroscopy (Chastain and King, 1995). Scofield atomic sensitivity factors and Shirley background deduction were used to determine the relative concentrations of elements expressed as an atomic percent (at $\%)$..

To produce a mean value of the lateral concentrations of the elements for fig 2 , survey scans were conducted on three different areas of trimmed pieces of both WSB_AR and WSB_IC.

Concentrations were calculated from peak areas for each element in each spectrum and the mean value and standard deviations calculated. The depth profile (z-axis) analysis using GCIB etching measured the relative concentrations of elements on the three different trimmed pieces of WSB_AR and the piece of WSB_IC. Those metallic elements occurring at concentrations $>1.0$ atomic percent (at\%), were compared to carbon, to quantify the relative reduction in the carbon concentration as a result of GCIB etching, for fig $3 a$ and $b$.

\subsection{Ultra Violet Ozone cleaning}

Samples were decontaminated using UV/O then evaluated with XPS, carbon combustion and pyGCMS. Three trimmed pieces of WSB_IC and WSB_AR were cleaned using UV/O using a Jelight-144AX UV/O cleaner ${ }^{\text {tm }}$ (Jelight Co Inc., Irvine, CA 92618, United States) for 20 minutes, according to the UV/O cleaning protocol reported by Cumpson and Sano (2013). Samples were

\section{Organic Material Removed by GCIB or UV/O}


then stored in upright glass vials in the same way as the WSB_AR. Py-GCMS, thermal combustion and XPS analysis was then used to evaluate the UV/O cleaning procedure.

\subsection{Pyrolysis-Gas Chromatography/Mass Spectrometry and Carbon Combustion}

Py-GCMS analysis was conducted according to Abbott et al., (2013) in triplicate on a core sample. Basalt sections were prepared in a laminar flow cabinet by milling $50 \mathrm{~g}$ to a powder in a UV/O cleaned agate pestle and mortar, and then passed through a thermally decontaminated, stainless steel, $150 \mu \mathrm{m}$ mesh sieve. Basalt powders were then stored in screw top glass vials (as described above). Samples were weighed (ca. $10 \mathrm{mg}$ ) into clean quartz pyrolysis tubes and plugged with dichloromethane extracted silica wool. Py-GCMS was conducted using a pulsed-mode open pyrolysis system using a CDS 1000 pyroprobe unit (CDS Analytical, USA) fitted with a platinum coil and a CDS 1500 valved interface operated at $320^{\circ} \mathrm{C}$. that fed into a Hewlett-Packard 6890GC split injector $\left(320^{\circ} \mathrm{C}\right.$ ) linked to a Hewlett-Packard 5973MSD (electron voltage $70 \mathrm{eV}$, filament current $220 \mathrm{uA}$, source temperature $230{ }^{\circ} \mathrm{C}$, quadrupole temperature $150{ }^{\circ} \mathrm{C}$, multiplier voltage $2200 \mathrm{~V}$., interface temperature $\left.320^{\circ} \mathrm{C}\right)$. Flash pyrolysis was carried out at $610^{\circ} \mathrm{C}$ for $10 \mathrm{~s}$. $(20$ ${ }^{\circ} \mathrm{C} . \mathrm{ms}^{-1}$ temperature ramp). The pyroprobe interface was maintained at $320{ }^{\circ} \mathrm{C}$ with the products passed into an HP6890 gas chromatograph (GC) with a $60 \mathrm{~m}$ HP-5MS column $(0.25 \mathrm{~mm}$ internal diameter, 0.25 um film thickness; J\&W Scientific, USA). A helium carrier gas was used at a flow rate of $1 \mathrm{~mL} \cdot \mathrm{min}^{-1}$. The $\mathrm{GC}$ was held at $50{ }^{\circ} \mathrm{C}$ for 1 minute and then the temperature was ramped from $50{ }^{\circ} \mathrm{C}$ to $310{ }^{\circ} \mathrm{C}$ at $5{ }^{\circ} \mathrm{C} \cdot \mathrm{min}^{-1}$ and held at final temperature for 12 minutes. Detection was achieved using an HP5972 series mass selective detector in full scan mode (50-650 a.m.u.). Data acquisition was controlled by an HP kayak XA Chem Station computer.

Total organic carbon (TOC) measurements were obtained for WSB_AR and WSB_IC both before and after decontamination by carbon combustion, using a CS230 Carbon/Sulfur Determinator (Leco Corporation, Michigan, U.S.A.) and were conducted in triplicate.

\section{RESULTS}

\subsection{Lateral XPS Measurements of WSB_AR and WSB_IC Element Concentrations}

XPS survey spectra of the WSB_AR and WSB_IC samples consistently showed clearly defined O, $\mathrm{Si} \mathrm{Al}, \mathrm{Mg}, \mathrm{Ca}, \mathrm{Fe}, \mathrm{Mn}$ and Ti core electron peaks, (Fig.1 is provided as an example). A

\section{Organic Material Removed by GCIB or UV/O}


comparison of the WSB_AR and WSB_IC spectra indicated no attenuating effects on either the peak intensities, or peak shape of high resolution spectra (see SI) specifically, between those elements detected at the low and higher binding energies. Furthermore, no changes in electron emission energies in any part of the XPS spectra resulting from the intentional addition of carbon, were observed.

XPS is capable of precise measurements (Briggs and Seah, 1983). However, to determine the accuracy of measurements the mean $(n=3)$ of the lateral concentration of the elements survey spectra of both WSB_AR and WSB_IC were obtained and compared to the reported values commonly cited for mid-ocean ridge basalts (MORB) (McBride and Gilmour, 2004), which is rutinely determined by X-ray fluorescence (XRF) (see fig 2). The Pearson coefficients of the correlation ( $\mathrm{r}$ ) between the reported elemental concentrations of MORB and the WSB_AR and WSB_IC samples was 0.98 and 0.97 respectively. These correlations provided confidence in the accuracy of the XPS measurements of the concentrations of the metallic elements and by implication measurements of carbon concentration using XPS. This provided confidence in the measurements made for the evaluation of the decontamination methods.

\subsection{Depth Profile Analysis to Evaluate Decontamination of WSB_AR and WSB_IC Using Gas Cluster Ion Beam Etching}

Elemental concentrations are derived from XPS spectral intensities. However, experimental setup, such as X-ray beam focus, size of analysis area or any variations in the sample topography, can cause variations in these intensities. Therefore, spectral intensities must be expressed as relative, rather than absolute values, and are expressed as a proportion of the total element composition in units of atomic percentage (at\%) (Watts and Wolstenholme, 2003). To assess relative changes in the carbon concentration (shown in Fig. 3a) it was essential that changes in the metallic element concentrations, as a result of GCIB sputter etching was assessed. Accordingly, the metallic element concentrations were measured during sputter etching and the concentrations of WSB_IC were plotted as a function of etch time (Fig $3 \mathrm{~b}$ inset). This indicated that there was minimal concentration variation of the metallic elements as a function of GCIB etch time and the sum of the elements occurring at concentrations $>1.0$ at $\%$ ( $\mathrm{Al}, \mathrm{Ca}, \mathrm{Fe}, \mathrm{Mg} \mathrm{Na}$, and $\mathrm{Si}$ ) was used as an unvarying standard to evaluate the relative changes in the carbon concentration.

\section{Organic Material Removed by GCIB or UV/O}


Fig 3a presents the proportional change in the carbon concentration in the WSB_IC and the mean carbon concentration of WSB_AR samples relative to the sum of the concentrations of the metallic elements as a function of GCIB sputter etch time. This showed that carbon concentrations decreased as a result of GCIB sputtering, relative to the unvarying concentrations of those elements. The WSB_IC carbon concentration exhibited an initial large decrease in the first 10 seconds of etching followed by a decline in carbon reduction between 20 and 90 seconds until a stable concentration with minimal variation was reached. The carbon concentration of the WSB prior to contamination, (WSB_AR) was added to fig 3a, to illustrate carbon reduction to precontamination levels.

\subsection{Decontamination using UV/ozone}

Decontamination of the entire surface of a material is required for bulk analysis by, for example py-GCMS, for which rock samples must be powdered prior to analysis. Here the purpose of the py-GCMS was to measure the effectiveness of UV/O decontamination rather than for detection of specific compounds as it is usually used. Trace levels of organic compounds comparable to the TOC values measured by carbon combustion $(0.041 \% \pm 0.05 \%)$, were not observed in the pyGCMS analysis of the WSB_AR internal volume (Fig 4a) indicating that adventitious carbon was not introduced during the preparative grinding and sieving. However the WSB_AR XPS measurements were 3.5 at $\%$

In contrast, a range of high molecular weight hydrocarbon compounds consistent with those found in WD40 residue were identified in WSB_IC using py-GCMS (Fig 4b) consistent with TOC values of $1.74 \% \pm 0.05 \%$. Following decontamination using UV/O treatment, the WD40 compounds were undetected by py-GCMS analysis (Fig 4c), furthermore the TOC values were reduced to $0.04 \% \pm 0.05 \%$, indicating that 20 minutes UV/O treatment removed WD40 hydrocarbons from the WSB samples.

Corroborative, XPS analysis indicated the carbon concentration of WSB_AR changes from 4.8 at $\%$ to $3.5 \pm 1.0$ at $\%$ following are UV/O cleaning. Whereas the intentional contamination increased carbon concentration to $22.3 \pm 3.0$ at $\%$ then after cleaning with 20 minutes UV/O to 3.0 \pm 2.7 at $\%$. These carbon concentrations were comparable to those of the intentionally contaminated sample after decontamination by 90 seconds of GCIB etching.

\section{Organic Material Removed by GCIB or UV/O}




\section{DISCUSSION}

To date, monatomic sputter etching has been used to remove carbonaceous materials from geological samples (Preston, 2011), as has UV/O cleaning (Nugent et al, 1998; Hausrath et al, 2007). However, GCIB sputter etching, most commonly used for surface analyses of semiconductors, has only recently been applied to the Earth Sciences. Sano et al. (2016) applied GCIB and UV/O decontamination prior to XPS, ToF SIMS and py-GCMS analysis detecting organic compounds consistent with remnant biological material. In our current study, we provide for the first time a rigorous and complete evaluation of the efficiency of decontamination procedures when coupled to XPS and bulk chemical analysis techniques, and show that these decontamination approaches can be considered useful as part of the application of surface analysis to different situations in Earth sciences and in planetary exploration.

\subsection{An evaluation of decontamination by GCIB}

Prior to evaluation of decontamination the accuracy of XPS when applied to the basalt was addresses by a number of considerations:

1. A comparisons of measured elemental compositions with those typically reported for basalts (fig 2, McBride and Gilmour 2004) was made and by implication the close correlation observed implies that the carbon concentration measured to assess decontamination are similarly accurate.

2. Since the GCIB gun used in this investigation was mounted within the XPS instrument, and analysis commenced immediately following GCIB etching, the possibility of recontamination or accumulation of carbon on the sample was eliminated.

3. The ultra-high vacuum drew away the sputtered material from the raster area, providing assurance that the high molecular weight organic compounds in the WD40 residue on the WSB_IC could not migrate from the raster perimeter to the analysis spot, between the repeated cycles of GCIB sputter etching.

4. During XPS analysis, the passage of the electrons emitted from the sample surface, through the intentionally added carbon, did not produce a detectable attenuation of their energy and by extension attenuation of the signal strength.

5. Observed changes in carbon concentrations with GCIB etching were not the result of relative changes in the metallic element concentrations (fig $3 \mathrm{~b}$ ), since no significant

\section{Organic Material Removed by GCIB or UV/O}


preferential sputter yields were detected for these elements. However, a 5.0 at $\%$ decrease in the $\mathrm{Si}$ concentration was observed. This may have been due to the removal of the $\mathrm{Si}$ in WD40 that was deposited during its application, or may have been due to minor differences in sputter yields for $\mathrm{Si}$, in comparison to the other elements. However this had no significant impact on the measurements.

With regards to the actual evaluation of decontamination the carbon concentration after intentional contamination (WSB_IC) at $\mathrm{t}=0$ seconds must be considered the sum of both the initial indigenous and the adventitious carbon as observed in the WSB_AR, plus the intentional contamination. Consistent with this assumption the carbon concentration of WSB_IC was reduced to a value less than the WSB_AR, following >90 seconds GCIB (fig 3a). This net decrease plausibly resulted from removal of both the adventitious carbon already present on WSB_AR, in addition to removal of the intentionally applied WD40 carbon. The carbon concentrations, observed at $\mathrm{t}>90$ seconds GCIB etching remained unchanged, regardless of etching time and are, therefore, considered indicative of the indigenous carbon. Corroboratively, the WSB_AR demonstrated an initial, albeit smaller decrease in the mean carbon concentration as a function of GCIB etch time here just indicating the removal of adventurous carbon associated with this sample. This demonstrates the ability of by XPS operating in conjunction with GCIB to discriminate between adventitious and indigenous carbon,

In terms of the mechanism of carbon removal GCIB can be regarded as a selective ion etching process. The sputter yield, which is the rate at which sputtering occurs for organic material, is many times that for inorganic material (Cumpson et al, 2013a). Therefore, although the decrease observed in carbon concentration in this study may be the result of the complete removal of the surface material in the raster area, including inorganic material and the attendant carbon, it is more likely due to preferential sputtering of carbon, with the removal of minimal amounts of noncarbon material. Regardless, of the mechanism, this study was able to evaluate removal of surface carbon from geological samples allowing the analysis of the underlying indigenous carbon.

The physical impact of GCIB etching and the depth distribution of adventitious and intentionally applied carbon is of interest but, because the basalt surface was uneven, it was not possible to measure surface topography by interferometry or atomic force microscopy and thus, measure sputter yields. Sputter yields could, however, be approximated using other data. Cumpson et al. (2013a) examined the etch rates of different materials and found that 1000 atom argon clusters

\section{Organic Material Removed by GCIB or UV/O}


with a total energy of $4 \mathrm{keV}$ produce sputter yields of $0.056 \mathrm{~nm} \cdot \mathrm{min}^{-1}$ in a purely $\mathrm{SiO}_{2}$ target and higher sputter yields of $23.86 \mathrm{~nm} . \mathrm{min}^{-1}$ for styrene targets. Since basalts are typically composed of $45 \%$ to $52 \% \mathrm{SiO}_{2}$ and styrene is an organic polymer, we anticipate that results obtained by Cumpson et al. (2013a) are an indicative framework for basalt sputter yields generally. This would produce an estimated final etch depth in the GCIB raster area of $0.084 \mathrm{~nm}$ after the minimum of 90 seconds needed to decontaminate the sample which implies that intentional and adventitious carbon were restricted to that depth range. The depth of analysis of XPS is up to $10 \mathrm{~nm}$ depending on the element being detected (Briggs and Grant 2003).

\subsection{The disparity between indigenous organic matter detected by XPS and trace carbon detected by GCMS after decontamination}

Although GCMS is sensitive to ppb concentrations of organic matter such material was not detected in the WSB_AR by this approach (Fig 4a). Additionally, WSB_AR bulk TOC measurements were at the limits of detection. However, basalts typically contain trace levels of organic carbon (Fristad, 2015) and carbonaceous material has been detected in basalt using XPS (Tingle et al, 1991) which is consistent with the carbon observed in low concentrations in both the WSB_AR and WSB_IC by XPS analysis after etch times $>90$ seconds. This trace material not detected by py-GCMS can likely be ascribable to the presence of carbonaceous films formed on cracks on reactive mineral surfaces such as silica (Jensen et al., 2014). Such carbonaceous material is considered thermally stabilised by olivine and other minerals and glasses and has been previously detected using XPS (Tingle and Hochella,1993; Johnson et al, 2015 ). Therefore thermally stable carbon may explain the discrepancy between the XPS and py-GCMS or TOC results for the WSB, since the later two rely upon thermal processes such as pyrolysis extraction (Py-GCMS) or carbon thermal combustion (TOC).

\subsection{Future Work}

In addition to quantitative elemental data, XPS spectra can also provide qualitative information regarding chemical states of samples. The purpose of this study was to quantitatively measure the removal of organic material on geological specimens. The high resolution XPS C1s spectra provide qualitative information regarding these chemical states but their analysis was outside the scope of this study. However, we provide $\mathrm{C} 1 \mathrm{~s}$ high resolution spectra in the supplementary information to indicate that chemical states data of indigenous carbon can be assessed in

\section{Organic Material Removed by GCIB or UV/O}


geological samples after decontamination. Surface analytical qualitative studies regarding the presence and nature of the indigenous carbon in other more biologically interesting basalts (e.g. Sano et al. 2016) and other geological specimens, is the subject of continued investigation, particularly the relevance of this carbon to the detection of molecular biomarkers for palaeo- and astrobiology investigations.

\section{CONCLUSION}

GCIB and UV/O treatment both equally significantly and demonstrably reduced the intentionally applied, and thus artificially high, surface organic contamination on a basalt sample. Furthermore, the indigenous carbon could be subsequently detected by XPS. GCIB should be conducted for at least 90 seconds but preferably 120 seconds with argon cluster sizes of 1000 atoms at $4 \mathrm{keV}$, which does not damage the surface chemistry. UV/O cleaning should be conducted for at least 20 minutes. These techniques do not require contact with samples, reducing the risk of introducing additional contamination thus increasing the confidence that basalt and by implication other geological samples containing trace levels of organic material can be decontaminated effectively using these methods, in preparation for the detection and analysis of molecular biomarkers in small, precious samples where destructive impact of the samples must be minimised.

\section{Acknowledgments}

The Author is deeply grateful for the bursary generously provided by The Leverhulme Trade Charities Trust without which this project would not be possible. Many thanks also to the IODP Gulf of Mexico repository in Texas for the supply of geological samples, and their kind assistance Thanks to all the team at NEXUS, Newcastle University. X-ray photoelectron spectra were obtained at the National EPSRC XPS Users' Service (NEXUS) at Newcastle University, an EPSRC Mid-Range Facility, and Paul Donohoe for operating the pyrolysis-GCMS.

\section{REFERENCES}

Abbott G.D., Swain E.Y., Muhammad A.B., Allton K., Belyea L.R. Laing, C.G. and Cowie G.L. (2013) 'Effect of watertable fluctuations on the degradation of Sphagnum phenols in surficial peats', Geochimica Et Cosmochimica Acta, 106, pp. 177-191.

Anders E. (1989) 'Pre-Biotic Organic-Matter from Comets and Asteroids', Nature, 342(6247), pp. 255-257.

Barlow A. J., Portoles J. F., and Cumpson P. J. (2014). Observed damage during Argon gas cluster depth profiles of compound semiconductors. Journal of Applied Physics, 116(5), 054908.

\section{Organic Material Removed by GCIB or UV/O}


Bateman M.D., Evans D.J.A. Buckland, P.C., Connell E.R., Friend R.J., Hartmann D., Moxon H., Fairburn W.A., Panagiotakopulu E. and Ashurst R.A., (2015). Last glacial dynamics of the Vale of York and North Sea lobes of the British and Irish Ice Sheet. Proceedings of the Geologists' Association, 126(6), pp.712-730.

Briggs D., and Grant J. T. (Eds.). (2003). Surface analysis by Auger and X-ray photoelectron spectroscopy.p.53 IM publications.

Briggs D. and Seah M.P., (1983). Practical surface analysis by Auger and X-ray photoelectron spectroscopy. D. Briggs, and M. P. Seah,(Editors), John Wiley and Sons, Chichester 1983, xiv+ 533.

Brocks J. and Banfield J. (2007). Molecular fossils and early life. In Geochimica Et Cosmochimica Acta Vol. 71, No. 15, pp. A123-A123).

Chastain J., and King R. C. (Eds.). (1995) Handbook of X-ray photoelectron spectroscopy: a reference book of standard spectra for identification and interpretation of XPS data. Eden Prairie, MN: Physical Electronics.

Cheng J. and Winograd N. (2006) 'Molecular depth profiling of multi-layer systems with cluster ion sources', Applied Surface Science, 252(19), pp. 6498-6501.

Cheng J., Wucher A. and Winograd N. (2006) 'Molecular depth profiling with cluster ion beams', Journal of Physical Chemistry $B, \mathbf{1 1 0}(16)$, pp. 8329-8336.

Cockell C.S. (2011) 'Life in the lithosphere, kinetics and the prospects for life elsewhere', Philos Transact A Math Phys Eng Sci, 369(1936), pp. 516-37.

Counsell J. D. P., Roberts, A. J., Boxford, W., Moffitt, C., and Takahashi, K. (2014). Reduced Preferential Sputtering of $\mathrm{TiO}_{2}$ using Massive Argon Clusters. Journal of Surface Analysis, 20(3), 211-215.

Cumpson P J and Seah M P (1996) Stability of reference masses. IV: Growth of carbonaceous contamination on platinumiridium alloy surfaces, and cleaning by UV/ozone treatment, Metrologia 33507

Cumpson P J. and Sano N. (2013) 'Stability of reference masses V: UV/ozone treatment of gold and platinum surfaces', Metrologia, 50(1), pp. 27-36.

Cumpson P.J., Portoles, J.F., Sano, N., Barlow, A.J., and Birch, M. (2013a) Depth profiling organic/inorganic interfaces by argon gas cluster ion beams: sputter yield data for biomaterials, in-vitro diagnostic and implant applications, Surf. Int. Anal. 45, 1859

Cumpson P. J., Portoles J. F., Barlow A. J., and Sano N. (2013b). Accurate argon cluster-ion sputter yields: Measured yields and effect of the sputter threshold in practical depth-profiling by x-ray photoelectron spectroscopy and secondary ion mass spectrometry. Journal of Applied Physics, 114(12), 124313.

Czanderna, A. W. (Ed.). (2012). Methods of surface analysis (Vol. 1). Elsevier.

Eglinton G. (1964) 'Hydrocarbons of biological origin from a one-billion-year-old sediment', Science, 145.3629 pp. 263 264.

Eigenbrode J., Benning L.G., Maule J., Wainwright N., Steele A., Amundsen H.E.F. and Team A. (2009) 'A Field-Based Cleaning Protocol for Sampling Devices Used in Life-Detection Studies', Astrobiology, 9(5), pp. 455-465.

Eigenbrode J.L. (2007) 'Fossil Lipids for Life-Detection: A Case Study from the Early Earth Record', Space Science Reviews, 135(1-4), pp. 161-185.

Fairley, N., (2009). CasaXPS Manual 2.3. 15: Introduction to XPS and AES. Casa Software. www.casaxps.com. accessed $8^{\text {th }}$ May 2017

Fitch F.J.a.M., J. A. (1967) 'The age of the Whin Sill', Geological Journal, 5(2), pp. 233-250.

Fristad, K. (2015) Personal communication Kirsten.Fristad@wwu.edu.

Furnes H. and Staudigel H. (1999) 'Biological mediation in ocean crust alteration: how deep is the deep biosphere?', Earth and Planetary Science Letters, 166(3-4), pp. 97-103.

Garrison B., J. and Postawa Z. (2013) 'Molecular dynamics simulations, the theoretical partner to dynamic cluster SIMS experiments', in Vickerman, J.C., and Briggs, D. (ed.) ToF-SIMS: surface analysis by mass spectrometry. 2 nd edn. I.M. Publications.

Goulty N.R. (2005). Emplacement mechanism of the Great Whin and Midland Valley dolerite sills. Journal of the Geological Society 162(6): 1047-1056.

Hausrath E.M., Treiman A.H., Vicenzi E., Bish D.L., Blake D., Sarrazin P., Hoehler T., Midtkandal I., Steele A. and Brantley S.L., (2008). Short-and long-term olivine weathering in Svalbard: implications for Mars. Astrobiology, 8(6), pp.1079-1092.

Jensen, S.J.K., Skibsted, J., Jakobsen, H.J., ten Kate, I.L., Guimlaugsson, H.P., Merrison, J.P., Finster, K., Bak, E., Iversen, J.J., Kondrup, J.C. and Nornberg, P. (2014) 'A sink for methane on Mars? The answer is blowing in the wind', Icarus, 236, pp. 24-27.

Johnson, K., Purvis, G., Lopez-Capel, E., Peacock, C., Gray, N., Wagner, T., März, C., Bowen, L., Ojeda, J., Finlay, N. and Robertson, S., (2015). Towards a mechanistic understanding of carbon stabilization in manganese oxides. Nature communications, 6 .

Liss D., Owens W.H. and Hutton D.H.W. (2004) 'New palaeomagnetic results from the Whin Sill complex: evidence for a multiple intrusion event and revised virtual geomagnetic poles for the late Carboniferous for the British Isles', Journal of the Geological Society, 161, pp. 927-938.

Mahoney C. M. (2010). Cluster secondary ion mass spectrometry of polymers and related materials. Mass spectrometry reviews, 29(2), 247-293.

McBride N. and Gilmour I. (2004), Chapter 2, An introduction to the solar system. Cambridge University Press.

\section{Organic Material Removed by GCIB or UV/O}


Mason S.L., Filley, T.R. and Abbott G.D. (2009). The effect of afforestation on the soil organic carbon (SOC) of a peaty gley soil using on-line thermally assisted hydrolysis and methylation (THM) in the presence of ${ }^{13} \mathrm{C}$-labelled tetramethylammonium hydroxide (TMAH) Journal of Analytical and Applied Pyrolysis, 85(1), 417-425.

Miyayama T., Sanada N., Bryan S. R., Hammond J. S., and Suzuki M. (2010). Removal of Ar+ beam-induced damaged layers from polyimide surfaces with argon gas cluster ion beams. Surface and Interface Analysis, 42(9), 14531457.

Naraoka H., Shimoyama A. and Harada K. (2000) 'Isotopic evidence from an Antarctic carbonaceous chondrite for two reaction pathways of extraterrestrial PAH formation', Earth and Planetary Science Letters, 184(1), pp. 1-7.

Nugent M.A., Brantley S.L., Pantano C.G. and Maurice P.A., (1998). 'The influence of natural mineral coatings on feldspar weathering'. Nature, 395(6702), pp.588-591.

Pizzarello S., Cooper G. W. and Flynn G. J. (2006) 'The nature and distribution of the organic material in carbonaceous chondrites and interplanetary dust particles', in Meteorites and the early solar system II. 1. University of Arizona Press, pp. 625-651.

Postawa Z. (2004). Sputtering simulations of organic overlayers on metal substrates by monoatomic and clusters projectiles. Applied surface science, 231, 22-28.

Preston L.J., Izawa M.R. and Banerjee N.R. (2011) 'Infrared spectroscopic characterization of organic matter associated with microbial bioalteration textures in basaltic glass', Astrobiology, 11(7), 585-99.

Rabbani S., Barber A. M., Fletcher J. S., Lockyer N. P., and Vickerman, J. C. (2011). TOF-SIMS with argon gas cluster ion beams: a comparison with C60+. Analytical chemistry, 83(10), 3793-3800.

Sano N., Purvis G.W., Barlow A.J., Abbott G.D., Gray N.N. and Cumpson P.J., 2016. Gas cluster ion beam for the characterization of organic materials in submarine basalts as Mars analogs. Journal of Vacuum Science and Technology A, 34(4), p.041405.

Shard A. G., Havelund R., Seah M. P., Spencer S. J., Gilmore I. S., Winograd N., ... and Moellers R. (2012). Argon cluster ion beams for organic depth profiling: results from a VAMAS interlaboratory study. Analytical chemistry, 84(18), 7865-7873

Shard A. G., Havelund R., Spencer S. J., Gilmore I. S., Alexander M. R., Angerer T. B., ... and Zhu Z. (2015). Measuring Compositions in Organic Depth Profiling: Results from a VAMAS Interlaboratory Study. The Journal of Physical Chemistry B, 119(33), 10784-10797.

Sherman L.S., Waldbauer J.R. and Summons R.E. (2007) 'Improved methods for isolating and validating indigenous biomarkers in Precambrian rocks', Organic Geochemistry, 38(12), pp. 1987-2000.

Smith J.W. and Kaplan I.R., 1970. Indigenous carbon in carbonaceous meteorites. Science, 167(3923), pp.1367-1370.

Staudigel H., Furnes H. and Smits M. (2014) 'Deep Biosphere Record of In Situ Oceanic Lithosphere and Ophiolites', Elements, 10(2), pp. 121-126.

Summons R.E., Albrecht P., McDonald G. and Moldowan J.M. (2007) 'Molecular Biosignatures', Space Science Reviews, 135(1-4), pp. 133-159.

Taborelli, M., (2007). Cleaning and surface properties. http://cds.cern.ch/record/1047073/files/p321.pdf. Accessed 3rd May 2017

Tingle, T.N., Mathez, E.A. and Hochella, M.F. (1991) 'Carbonaceous Matter in Peridotites and Basalts Studied by Xps, Sali, and Leed', Geochimica Et Cosmochimica Acta, 55(5), pp. 1345-1352.

Tingle T.N. and Hochella M.F. (1993) 'Formation of Reduced Carbonaceous Matter in Basalts and Xenoliths - Reaction of C-O-H Gases on Olivine Crack Surfaces', Geochimica Et Cosmochimica Acta, 57(14), pp. 3245-3249.

Vig J.R. (1985) 'UV ozone Cleaning of Surfaces', Journal of Vacuum Science and Technology a-Vacuum Surfaces and Films, 3(3), pp. 1027-1034.

Watts J.F. and Wolstenholme J. (2003) An Introduction to SURFACE ANALYSIS by XPS and AES Wiley Chichester.

Winograd N., Postawa Z., Cheng J., Szakal C., Kozole J., and Garrison B. J. (2006). Improvements in SIMS continue: Is the end in sight?. Applied surface science, 252(19), 6836-6843.

Yamada I., Matsuo J., Toyoda N., and Kirkpatrick A. (2001). Materials processing by gas cluster ion beams. Materials Science and Engineering: R: Reports, 34(6), 231-295

\section{Organic Material Removed by GCIB or UV/O}




\section{FIGURE LEGENDS}

FIG.1. An example of an XPS survey spectrum of Whin Sill basalt. The major element peak assignments are labelled in bold and Auger peaks are labelled in italics (see Fairly, 2009).

FIG.2. Mean composition of metals in the mid-ocean ridge basalt (MORB) (cross hatched) measured by XRF (McBride and Gilmour, (2004) compared to those occurring at $>1$ at $\%$ in Whin Sill basalt as received (WSB_AR) $(n=3)$ (solid) and intentionally contaminated WSB_IC $(n=3)$ (dots) as measured by XPS, with error bars for the data obtained in this study indicating 1 standard deviation.

FIG.3a. XPS measurements to obtain the surface concentrations of carbon as a function of argon GCIB sputter etch time in WSB_IC (intentionally contaminated) $(n=1)$ and WSB_AR (as received) basalt samples $(\mathrm{n}=3)$. The carbon surface concentration of WSB_AR prior to intentional contamination has been included in the plot (AR) to show increases in surface concentration as a result of intentional contamination. 3b Major metallic elemental concentrations of WSB_IC, as function of GCIB etching time. The Error bars on the WSB (AR) represent one standard deviation $(n=3)$.

FIG.4 a-c. Py-GCMS Chromatograms of (a) WSB_AR showing trace levels of contamination followed by (b) WSB_IC, prior to cleaning demonstrating the presence of a range of organic compounds consistent with those found inWD40 followed by (c) WSB_IC which was cleaned using UV ozone (UV/O) for $20 \mathrm{~m}$, showing that trace levels of organic compounds are observed. This is a non-quantitative study and the composition of WD40 is understood therefore the assignment of peaks to specific compounds is not germane.

\section{Supplementary Information}

Examples of the $\mathrm{C} 1 \mathrm{~s}$ spectra obtained during this investigation, demonstrating that this data can be obtained the basalt samples.

\section{Organic Material Removed by GCIB or UV/O}




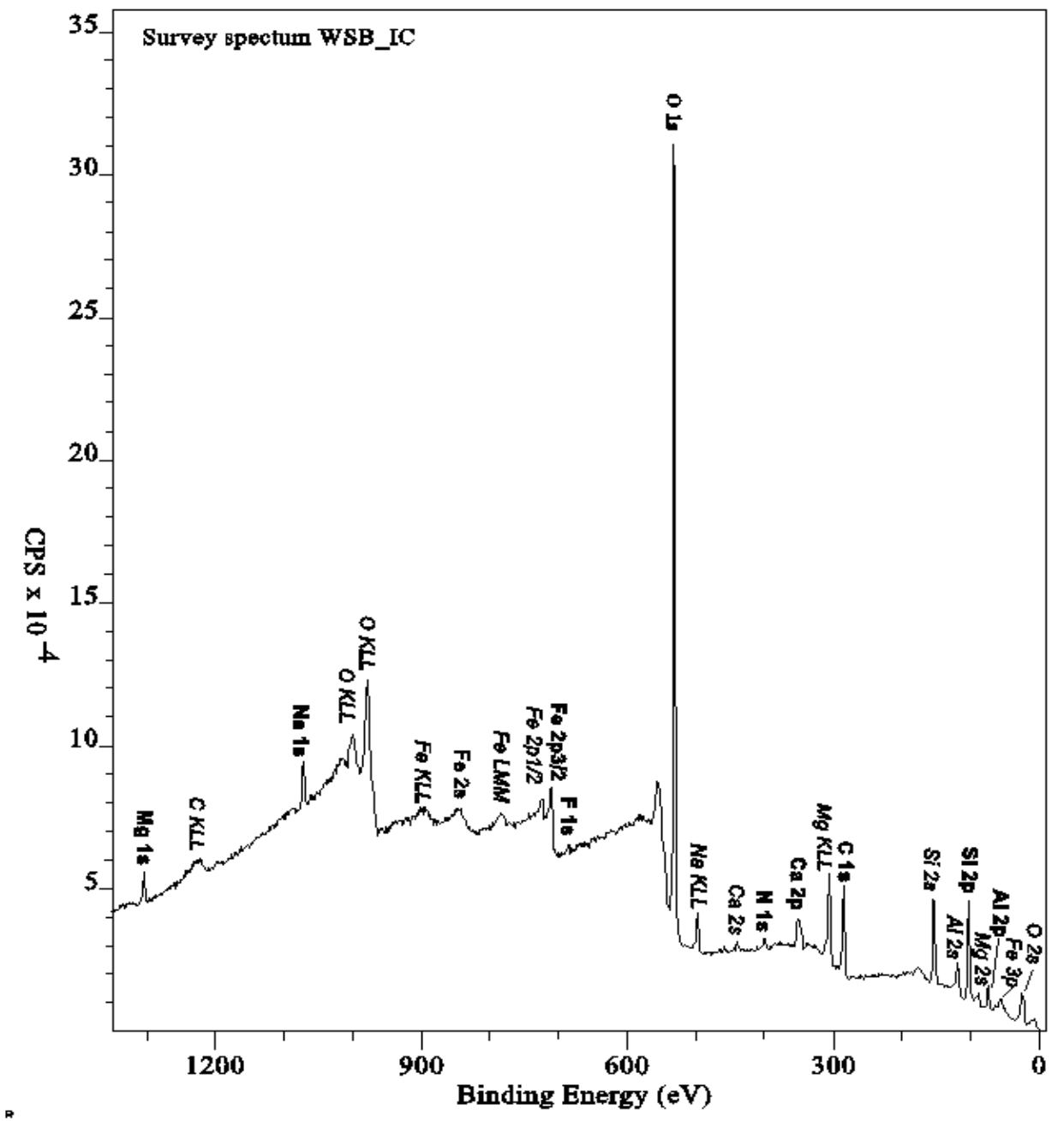

Fig. 1

Organic Material Removed by GCIB or UV/O 


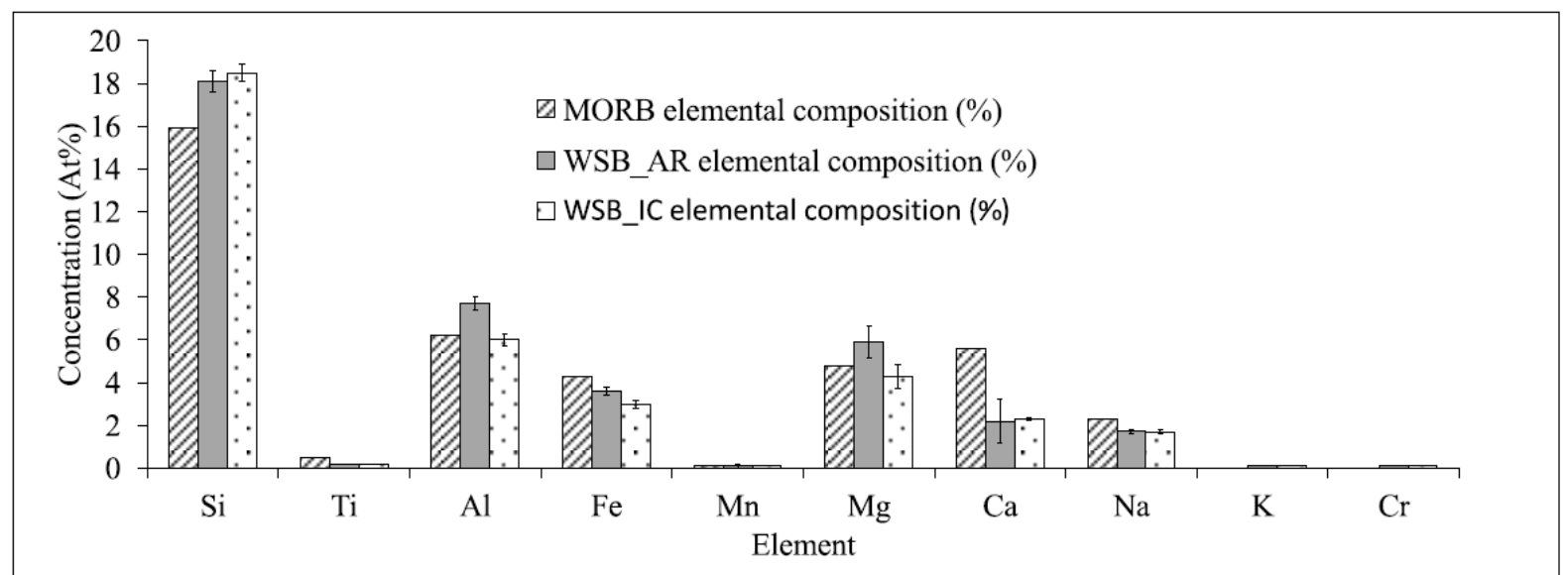

Fig. 2

Organic Material Removed by GCIB or UV/O 


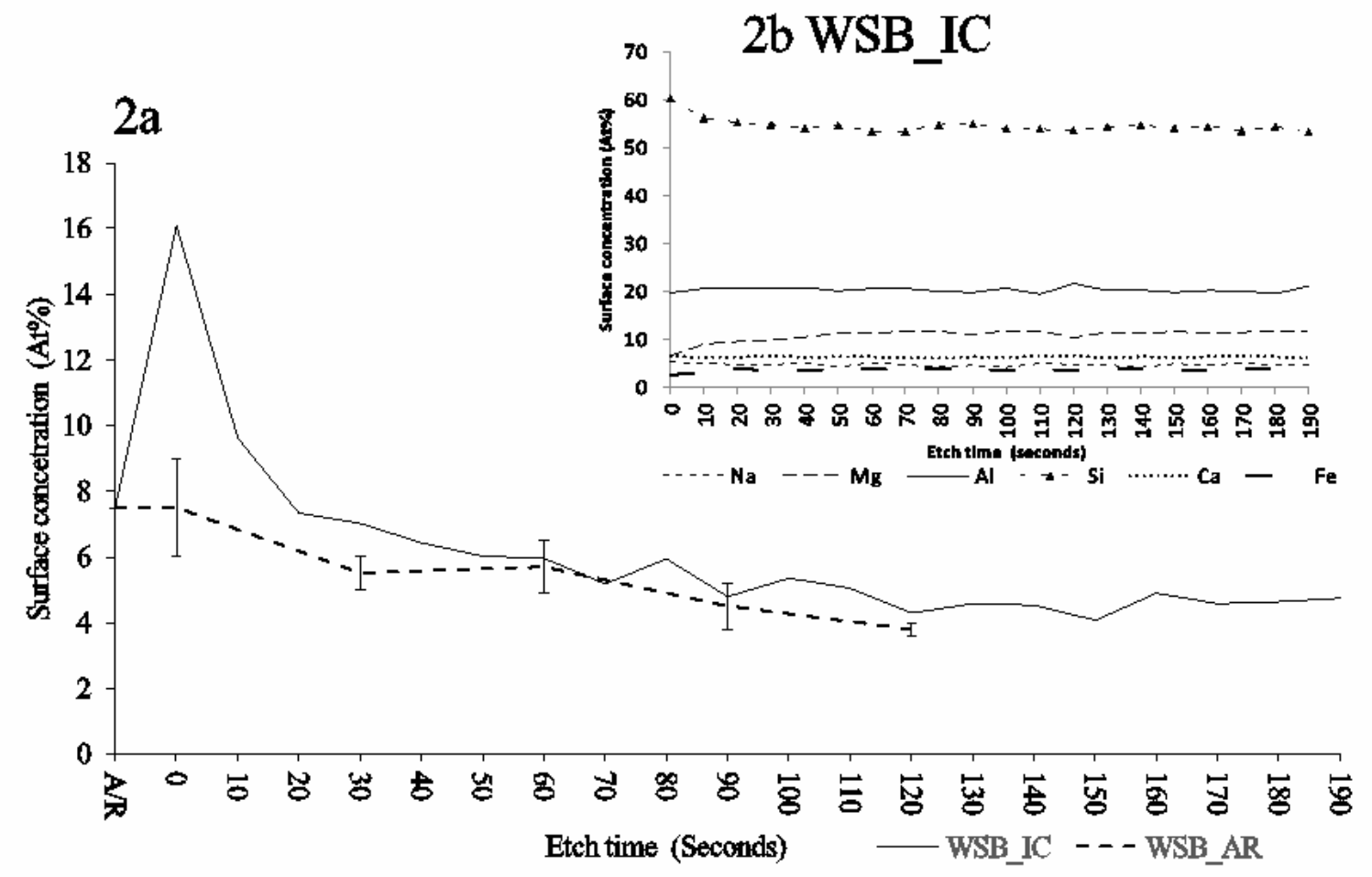

Fig. 3

Organic Material Removed by GCIB or UV/O 


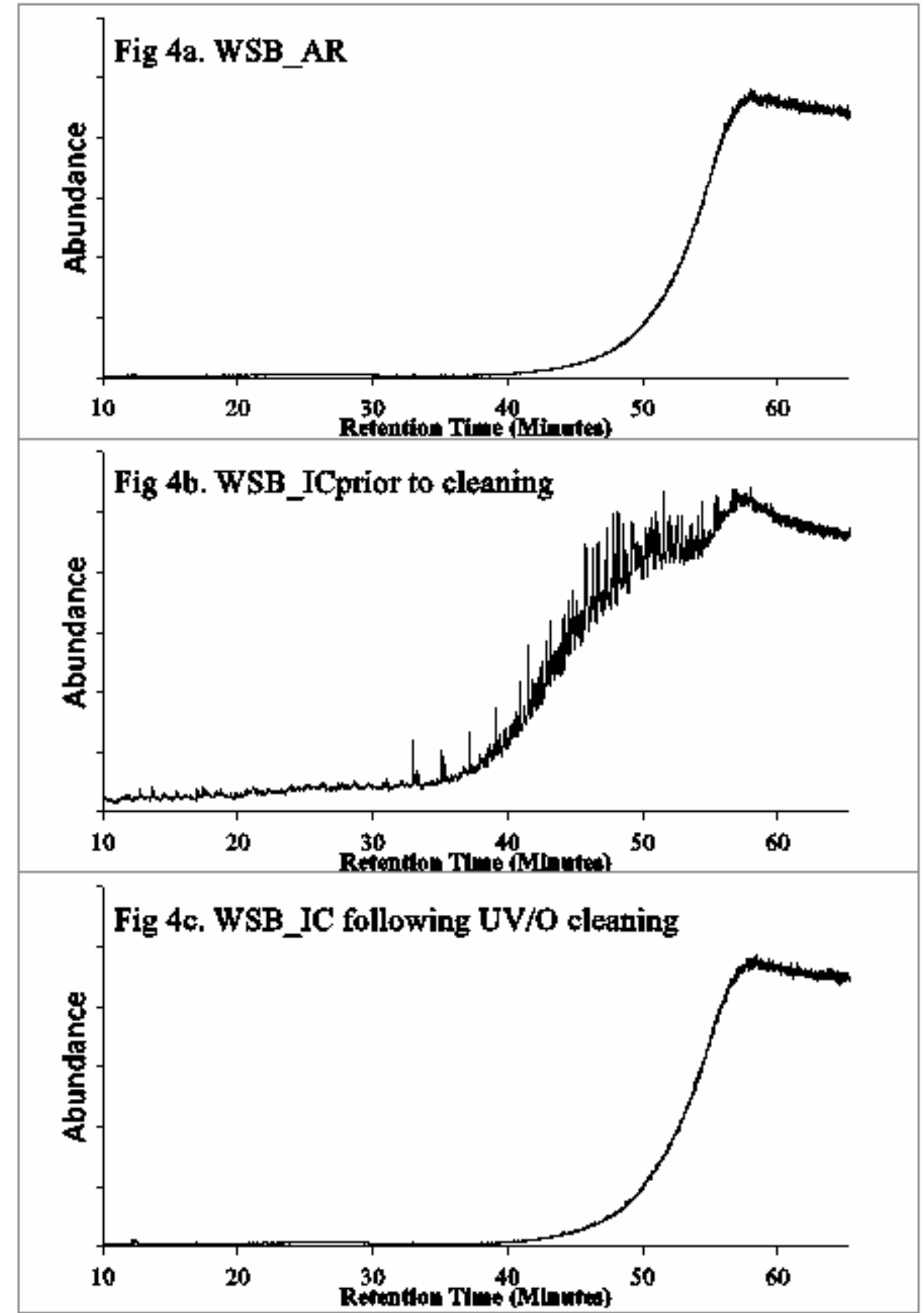

Fig. 4

Organic Material Removed by GCIB or UV/O 